\title{
Follow-up Clinical Electrophysiological Studies in a Patient with Myotonic Dystrophy
}

\author{
Shuichi HIROMASA, Makoto AKIYAMA*, Takayuki IKEDA, \\ Shigeo TAKATA and Kenichi KOBAYASHI
}

\begin{abstract}
A 38-year-old male myotonic dystrophy patient with left hemiblock, bradycardia and ventricular arrhythmias underwent electrophysiologic studies 19 months after he developed dizziness. Rapid and significant progression of binodal disease required implantation of a permanent pacemaker, which responded favorably. We suggest that careful monitoring or electrophysiologic studies are indicated in patients with these findings.
\end{abstract}

Key words: Repeat electrophysiological study, Ambulatory electrocardiogram, Conduction disturbance, Permanent pacemaker implantation

Myotonic dystrophy (Steinert's disease), an autosomal dominant neuromuscular disorder, is characterized by myotonia and myopathic changes and also cataract formation, gonadal atrophy, frontal baldness and mental impairment. It is well known that cardiac involvement in this disease is frequent, usually affecting the specialized conducting system, and there is development of abnormal impulse formation and conduction abnormalities (1-3). However, very few serial clinical electrophysiological studies using His-bundle electrogram recordings have been reported for evaluation of the progression of conduction system involvement in this disease (4). In that study, several progressions of infranodal conduction disease were detected.

\section{CASE REPORT}

Previously, we reported a family afflicted with this hereditary condition that showed mostly diffuse infranodal cardiac conduction disturbances (5). One of the affected individuals of this family (a 38-yearold man) was found to have first degree atrioventricular block (PR interval of $0.24 \mathrm{~s}$ ), left anterior fascicular block (frontal ORS axis $-50^{\circ}$ ) and sinus bradycardia at a rate of 53 beats $/ \mathrm{min}$ (5). Although the patient was asymptomatic, an electrophysiologic study was performed in September 1983 in view of the electrocardiographic abnormalities and the strong presence of cardiac conduction disturbances in his family. Hisbundle electrocardiogram revealed $\mathrm{HV}$ interval prolongation $(75 \mathrm{~ms})$. This finding suggested that the first degree atrioventricular block was associated with a depressed His-Purkinje conduction system, especially in the left anterior fascicle, most likely the result of myotonic dystrophy.

The patient was closely monitored clinically and electrocardiographically. Eighteen months after the first study, he developed dizziness. Serial standard electrocardiograms revealed no changes (Fig. 1). However, continuous ambulatory electrocardiographic monitoring disclosed $2.10 \mathrm{~s}$ pauses, second degree atrioventricular block (Wenckebach type) and episodes of Wenckebach ectopic atrial contractions (Fig. 2) as well as frequent premature ventricular captures. In view of this obvious progression of his conduction system disease, sinus node dysfunction and frequent premature ventricular captures, which

From The First Department of Internal Medicine, Kanazawa University School of Medicine, Kanazawa and *The Second Department of Internal Medicine, Toyama Medical and Pharmaceutical University, Toyama

Received for publication April 28, 1990; Accepted for publication November 20, 1990

Reprint requests should be addressed to Shuichi Hiromasa, MD, Cardiovascular Division,

Sakamoto Hospital, 3345-2 Nyuzen, Nyuzen-machi, Shimoniikawa-gun, Toyoma 939-06, Japan 


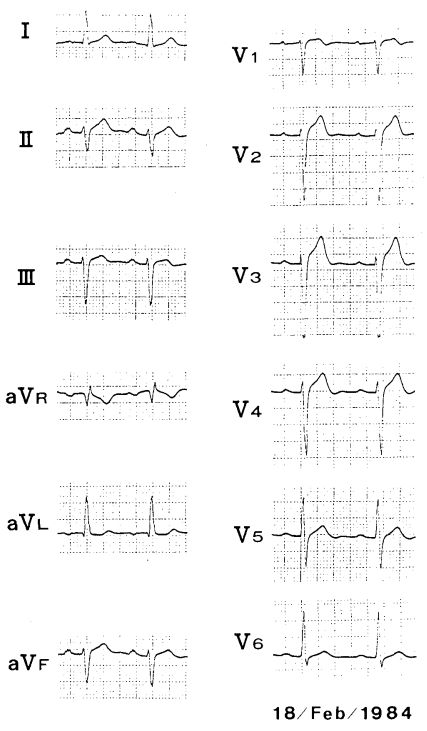

Fig. 1. Twelve-lead electrocardiogram obtained 18 months after the first study.

might be associated with ventricular tachycardia in this group of patients (6), a repeat electrophysiologic study, 19 months after the first one, was performed. It revealed an $\mathrm{HV}$ interval of $83 \mathrm{~ms}$ (an increase of $8 \mathrm{~ms}$ over the first study). Also, the sinoatrial conduction time (SACT), sinus node recovery time (SRT) and atrioventricular-nodal effective refractory period (AVN-ERP) were prolonged, and the Wenckebach point was decreased, suggesting new
Table. Electrophysiological Findings

\begin{tabular}{llcc}
\hline & & $\begin{array}{l}\text { First } \\
\text { study }\end{array}$ & $\begin{array}{l}\text { Second } \\
\text { study }\end{array}$ \\
\hline A-A & $(\mathrm{ms})$ & 660 & 780 \\
SACT & $(\mathrm{ms})$ & 105 & $128^{*}$ \\
SRT & $(\mathrm{ms})$ & 1,050 & $1,440^{*}$ \\
PA & $(\mathrm{ms})$ & 25 & 25 \\
AH & $(\mathrm{ms})$ & 140 & $145^{*}$ \\
HV & $(\mathrm{ms})$ & $75^{*}$ & $83^{*}$ \\
Wenckebach point & $(\mathrm{bpm})$ & 130 & $110^{*}$ \\
BCL & $(\mathrm{ms})$ & 600 & 600 \\
At-ERP & $(\mathrm{ms})$ & 240 & 190 \\
At-FRP & $(\mathrm{ms})$ & 260 & 210 \\
AVN-ERP & $(\mathrm{ms})$ & 330 & $410^{*}$ \\
AVN-FRP & $(\mathrm{ms})$ & 450 & 500 \\
V-ERP & $(\mathrm{ms})$ & 190 & 250 \\
V-FRP & $(\mathrm{ms})$ & 230 & 270 \\
\hline
\end{tabular}

* abnormal value; SACT, sinoatrial conduction time; SRT, sinus node recovery time; BCL, basic cycle length; At, atrial; AVN, atrioventricular nodal; V, ventricular; ERP, effective refractory period; FRP, functional refractory period

binodal disease (Table). Programmed electrical stimulation failed to induce ventricular tachycardia. Subsequently, a permanent pacemaker was implanted and the patient remains asymptomatic.

\section{DISCUSSION}

Myotonic dystrophy is generally associated with multiple cardiac rhythm disturbances, and sudden death, often secondary to high degree atrioventric-

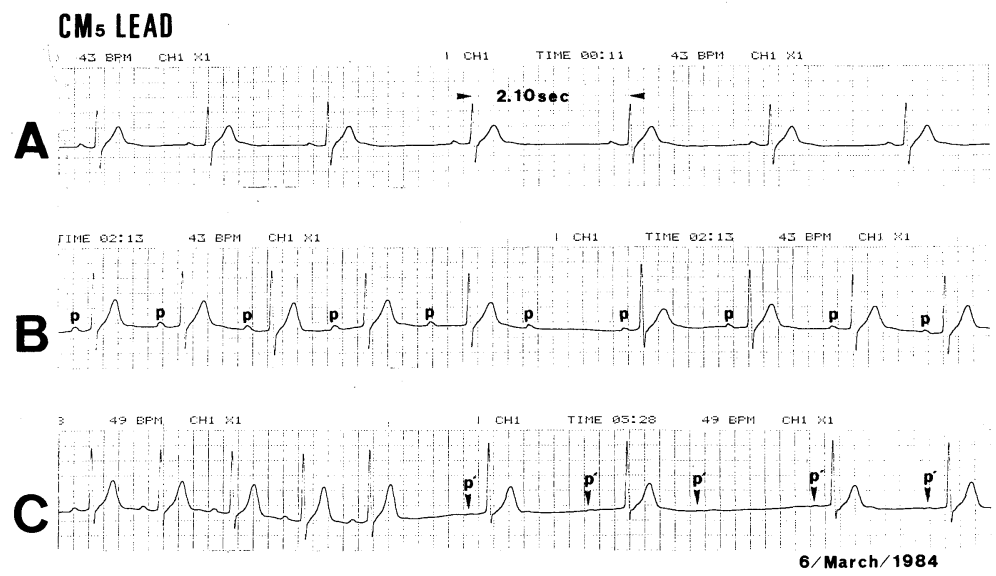

Fig. 2. Ambulatory continuous electrocardiographic recording, obtained 18 months after the first study, showing a $2.10 \mathrm{~s}$ pause (A), second degree atrioventricular block (Wenckebach type) (B), and episodes of Wenckebach ectopic atrial conduction $(\mathrm{C})$. 
ular block, but also possibly related to ventricular tachycardia (6). Progression of conduction system disease in these patients has been evaluated before by Prystowsky and co-workers (4) by means of electrophysiological studies. They evaluated serially 9 patients afflicted with this disorder and concluded that if significant disease is detected in the conducting system, permanent pacemaker implantation is required. The present patient was found to have both sinus node and atrioventricular node dysfunction in addition to His-Purkinje system depression which affected the left anterior fascicle in particular (Table). While serial electrocardiograms failed to detect progression of disease, careful clinical followup and ambulatory electrocardiographic monitoring, revealed the presence of further conducting system disease. A repeat electrophysiological study confirmed the presence of sinoatrial and atrioventricular nodal disease requiring the implantation of a permanent pacemaker.

Electrophysiological testing is not routinely recommended in asymptomatic patients with myotonic dystrophy. However, when continuous ambulatory electrocardiographic monitoring detects new changes such as the ones described here, new electrocardiographic abnormalities or if new symptoms develop, electrophysiological testing might become mandatory for pacemaker implantation or antiarrhythmic therapy if necessary. This is due to the apparently higher incidence of serious conduction system abnormalities and ventricular dysrhythmias associated with sudden death in these patients.

\section{REFERENCES}

1) Griggs RC, Davis RJ, Anderson DC, Dove JT. Cardiac conduction in myotonic dystrophy. Am J Med 59: 37, 1975.

2) Hiromasa S, Ikeda $T$, Kubota $K$, et al. Myotonic dystrophy: Ambulatory electrocardiogram, electrophysiologic study, and echocardiographic evaluation. Am Heart J 113: 1482, 1987.

3) Uemura $\mathrm{N}$, Tanaka $\mathrm{H}$, Niimura $\mathrm{T}$, et al. Electrophysiological and histological abnormalities of the heart in myotonic dystrophy. Am Heart J 86: 616, 1973.

4) Prystowsky EN, Pritchett ELC, Roses AD, Gallagher $\mathrm{J}$. The natural history of conduction system disease in myotonic muscular dystrophy as determined by serial electrophysiologic studies. Circulation 60: 1360, 1979.

5) Hiromasa S, Ikeda T, Kubota K, et al. A family with myotonic dystrophy associated with diffuse cardiac conduction disturbances as demonstrated by His bundle electrocardiography. Am Heart J 111: 85, 1986.

6) Hiromasa $S$, Ikeda $T$, Kubota $K$, et al. Ventricular tachycardia and sudden death in myotonic dystrophy. Am Heart J 115: 914, 1988. 